\title{
A Sub-1V Bandgap Reference Circuit Using Subthreshold Current
}

\author{
Hongchin Lin \\ Department of Electrical Engineering \\ National Chung-Hsing University \\ Taichung, Taiwan \\ e-mail:hclin@dragon.nchu.edu.tw
}

\author{
Chao-Jui Liang \\ Department of Electrical Engineering \\ National Chung-Hsing University \\ Taichung, Taiwan
}

\begin{abstract}
A bandgap reference circuit employing subthreshold current is proposed. Only a small fraction of $V_{B E}$ is utilized to generate the reference voltage of $170 \mathrm{mV}$. Since the subthreshold current of MOSFET's is used as the current source, the circuit only consumes $2.4 \mu \mathrm{W}$ at supply voltage of $1 \mathrm{~V}$. It was fabricated using $0.18 \mu \mathrm{m}$ CMOS triple-well technology on chip area of $0.029 \mathrm{~mm}^{2}$. Both of the measurement and the simulation demonstrate the reference voltage variation is $1.3 \mathrm{mV}$ from $-20^{\circ} \mathrm{C}$ to $100^{\circ} \mathrm{C}$ and is $1.1 \mathrm{mV}$ per volt for supply voltage from $0.95 \mathrm{~V}$ to $2.5 \mathrm{~V}$.
\end{abstract}

\section{INTRODUCTION}

The reference voltage generator is required in many analog and mixed-signal circuits, such as ADC, DAC, DRAM and flash memories, and so forth. It provides a constant reference voltage independent of process, temperature, and supply voltage variation. The bandgap reference (BGR) is the most stable and popular reference voltage generators [1][2]. However, the reference voltage is usually about $1.2 \mathrm{~V}$ which requires the supply voltage to be over $1.5 \mathrm{~V}$, and thus limits the applications at very low supply voltages. Even though many efforts have been done to reduce the reference voltage lower then $1.2 \mathrm{~V}$ for sub- $1 \mathrm{~V}$ operation [3][4], they required operational amplifiers (OP) which result in larger power consumption, larger chip area and more difficult OP design. The new trend tries to employ the subthreshold characteristics of MOSFET's to generate low reference voltages for sub-1V operation [5][6]. However, due to mobility and threshold voltage variation with temperature and process corners, the reference voltage variation is much larger than the BGR.

This work proposes a simple BGR circuit using subthreshold current without OP's for low-power sub-1V operation. The key idea is that a small fraction of $V_{B E}$ in parasitic bipolar transistors and the difference of two $\mathrm{V}_{\mathrm{BE}}$ 's are combined to generate the reference voltage of $170 \mathrm{mV}$.

\section{THE PROPOSED BGR CIRCUIT}

Fig. 1 illustrates the simplified sub-1V BGR core circuit. The area ratio of NPN transistors $\mathrm{Q}_{1}$ to $\mathrm{Q}_{2}$ is $N$. The current source can be provided by a subthreshold current generator. If the base current of $\mathrm{Q}_{2}$ is much smaller than the current through $\mathrm{R} 1$ and $\mathrm{R} 2$, the node voltage $\mathrm{V}_{1}$ can be approximated as

$$
V_{1}=V_{B E 2}+\frac{R 1}{R 2} V_{B E 2}
$$

Note that $V_{1}$ is proportional to $V_{B E 2}$ which has the negative temperature coefficient. If $\mathrm{V}_{1}$ is subtracted from $\mathrm{V}_{\mathrm{BE} 1}$, the reference voltage Vref $\left(\mathrm{V}_{\mathrm{CE} 2}\right)$ can be expressed as

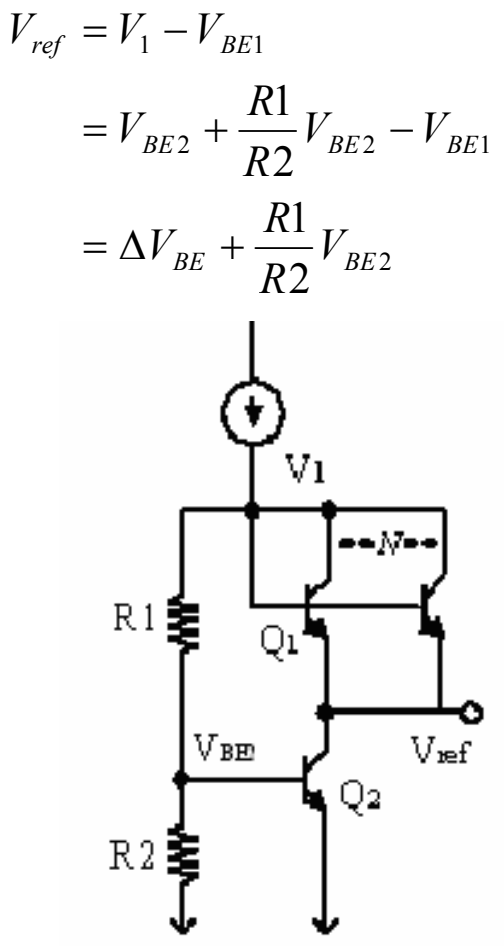

Fig. 1 The simplified BGR core circuit

If $\mathrm{Q}_{1}$ is diode-connected and $\mathrm{Q}_{2}$ is operated at forward active mode or near saturation, as long as the ratio $(\beta)$ of the collector current $\left(\mathrm{I}_{\mathrm{C} 2}\right)$ to the base current $\left(\mathrm{I}_{\mathrm{B} 2}\right)$ is large enough, due to $\mathrm{I}_{\mathrm{E} 1}=\mathrm{I}_{\mathrm{C} 2}$, we may have

$$
\Delta V_{B E}=V_{B E 2}-V_{B E 1}=\frac{K T}{q} \ln \left(\frac{\beta+1}{\beta} N\right) \approx \frac{K T}{q} \ln N
$$

In our mixed-mode $0.18 \mu \mathrm{m}$ CMOS technology, the deep n-well process is a standard built-in layer for the p-type substrate wafers in order to have individual well potentials for any N-MOS and P-MOS transistors. Thus, there is no extra cost to have NPN parasitic transistors.

Since the NPN transistors are the parasitic components, the current gain $\beta=\mathrm{I}_{\mathrm{C}} / \mathrm{I}_{\mathrm{B}}$ can be expected not 
to be high. To verify $\beta$ of the NPN transistor $\mathrm{Q}_{2}$ is high enough, Fig. 2 demonstrates the $\beta$ value is around 17 at room temperature when $\mathrm{V}_{\mathrm{BE}}$ is $0.7 \mathrm{~V}$ and $\mathrm{V}_{\mathrm{CE}}$ is over $0.16 \mathrm{~V}$. In our design, the reference voltage equal to $\mathrm{V}_{\mathrm{CE}}$ of $\mathrm{Q}_{2}$ is $0.17 \mathrm{~V}$, which makes $\mathrm{Q}_{2}$ close to saturation. Even though the $\beta$ value is still quite close to the $\beta=18$ at forward active mode, the BGR circuit still works well. However, if $\mathrm{V}_{\mathrm{CE}}$ is chosen to be lower than $0.14 \mathrm{~V}$, the BGR circuit could not work normally, because $\mathrm{Q}_{2}$ enters deep saturation and the base current in $\mathrm{Q}_{2}$ is no longer negligible compared to the current through R1 and R2.

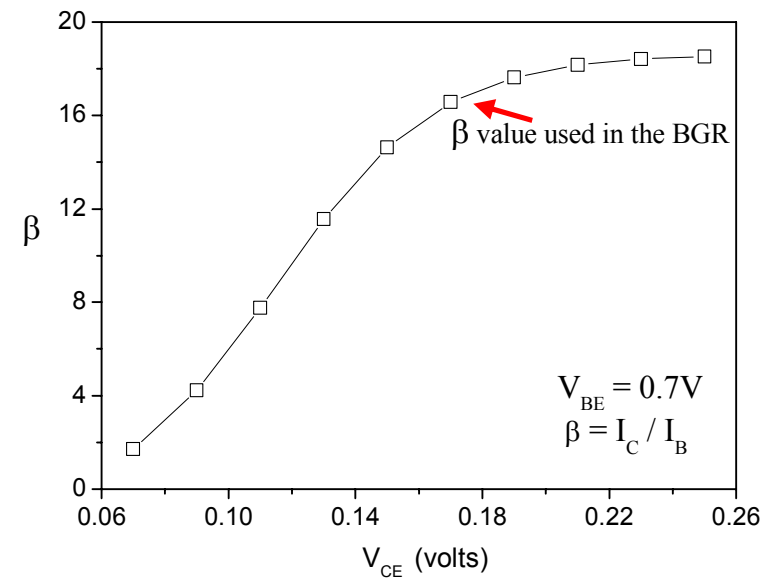

Fig. 2 The ratio $(\beta)$ of the collector current $\left(I_{C}\right)$ to the base current $\left(\mathrm{I}_{\mathrm{B}}\right)$ is a function $\mathrm{V}_{\mathrm{CE}}$ when $\mathrm{V}_{\mathrm{BE}}=0.7 \mathrm{~V}$.

After Eqn. (3) is substituted into Eqn. (2), the reference voltage is obtained.

$$
V_{\text {ref }}=\frac{K T}{q} \ln N+\frac{R 1}{R 2} V_{B E 2}
$$

Since the ratio R1/R2 can be chosen to be smaller than one in order to have a fractional portion of bandgap reference, which is around $1.25 \mathrm{~V}$, the transistor ratio $N$ can be smaller to generate low reference voltage, Vref. In our design, $\mathrm{R} 1 / \mathrm{R} 2=13 / 80$ and $N=8$. That is why it can be operated at supply voltage lower than $1 \mathrm{~V}$.

The complete BGR circuit shown in Fig. 3 includes the start-up circuit using $\mathrm{M}_{6}, \mathrm{M}_{7}$ and $\mathrm{C}_{\mathrm{P}}$, the subthreshold current generator composed of $M_{1}$ to $M_{4}$ and $R_{S}$, and the BGR core circuit utilizing $\mathrm{M}_{5}, \mathrm{Q}_{1}, \mathrm{Q}_{2}, \mathrm{R} 1$ and $\mathrm{R} 2$. The detailed dimensions of the devices are listed in Table I.

The N-MOSFET's in the subthreshold current generator can be operated in strong or weak inversion depending on the current through M1 and M2. The smaller current can make them in weak inversion. Since the drain current in weak inversion can be expressed as [7]

$$
V_{G S}=n \frac{K T}{q} \ln \frac{I_{D}}{(W / L) I_{D 0}}
$$

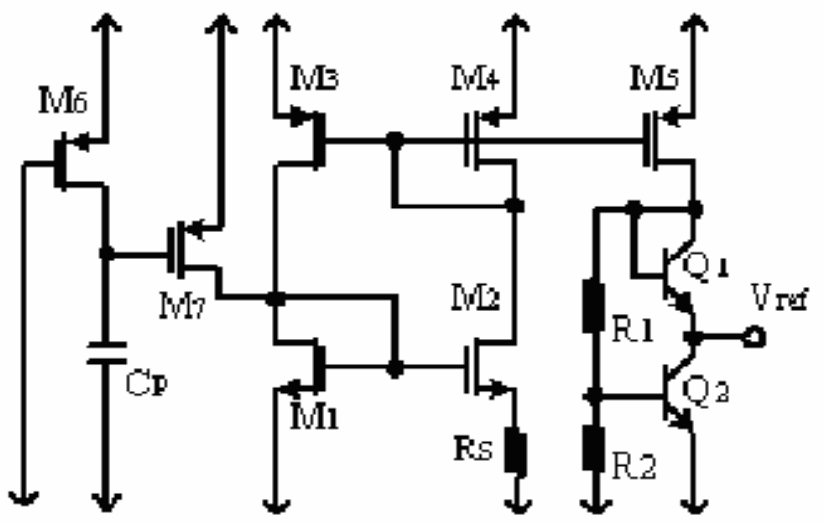

Fig. 3 The complete sub-1V BGR circuit including the start-up circuit

Thus, the voltage drop across RS is

$$
V_{R S}=\Delta V_{G S}=V_{G S 1}-V_{G S 2}=n \frac{K T}{q} \ln \left[\frac{(W / L)_{2} I_{1}}{(W / L)_{1} I_{2}}\right]
$$

where $n=1+C_{d} / C_{O X}, \quad C_{d}$ is the surface depletion capacitance, $C_{O X}$ is the gate oxide capacitance. If $I_{I}$ is chosen to be equal to $I_{2}$ by using current mirrors of $\mathrm{M}_{3}$ and $\mathrm{M}_{4}$, the current through RS can be written as

$$
I_{2}=\frac{V_{R S}}{R_{S}}=\frac{n}{R_{S}} \frac{K T}{q} \ln \left[\frac{(W / L)_{2}}{(W / L)_{1}}\right]
$$

Therefore, the currents through $\mathrm{M}_{1}$ and $\mathrm{M}_{2}$ are nearly independent of the supply voltage. Even though the current may be slightly increased as the temperature is increased, the currents in the NPN transistors are also increased. The more important point is the voltage drop in the NPN transistors is a logarithmic function of current. The reference voltage can still keep nearly constant for small current variations.

Table I The device parameters for Fig. 3

\begin{tabular}{||c|c||c|c|}
\hline \hline Device & $\mathrm{W} / \mathrm{L}$ & Device & Resistance \\
\hline $\mathrm{M}_{1}$ & $2 / 2$ & $\mathrm{R} 1$ & $130 \mathrm{~K} \Omega$ \\
\hline $\mathrm{M}_{2}$ & $100 / 2$ & $\mathrm{R} 2$ & $800 \mathrm{~K} \Omega$ \\
\hline $\mathrm{M}_{3}$ & $25 / 6$ & $\mathrm{RS}$ & $350 \mathrm{~K} \Omega$ \\
\hline $\mathrm{M}_{4}$ & $25 / 6$ & Device & Emitter area \\
\hline $\mathrm{M}_{5}$ & $28 / 2$ & $\mathrm{Q}_{1}$ & $2 \mu \mathrm{m} \times 2 \mu \mathrm{m} \times 8$ \\
\hline $\mathrm{M}_{6}$ & $1 / 20$ & $\mathrm{Q}_{2}$ & $2 \mu \mathrm{m} \times 2 \mu \mathrm{m}$ \\
\hline $\mathrm{M}_{7}$ & $60 / 1$ & & \\
\hline
\end{tabular}

The other important issue in the subthreshold current generator is the existence of bi-stable bias points, one of which may turn off the current generator. Therefore, the start-up circuit was used to drive the circuit to the desired bias point when the supply is turned on. The operation is that $\mathrm{M}_{6}$ provides a current to charge $\mathrm{C}_{\mathrm{P}}$. If the gate voltage of $M_{7}$ is not high enough, the drain current of $M_{7}$ charges 
the gate voltages of $M_{1}$ and $M_{2}$ to the desired bias level. $M_{7}$ stops conducting current until its gate voltage is high enough, so the start-up circuit does not consume any power after the BGR circuit reaches the steady state.

\section{SIMULATION AND MEASUREMENT RESULTS}

The sub-1V and subthreshold BGR circuit was designed and fabricated using $0.18 \mu \mathrm{m}$ triple-well CMOS technology. The parasitic $n+/ p$-well/deep n-well structure provides the NPN bipolar transistors. Even though the forward active current gain $\left(\mathrm{I}_{\mathrm{C}} / \mathrm{I}_{\mathrm{B}}\right)$ is only around 18 , it is good enough in our applications. Note that the triple well structure makes $\mathrm{Q}_{1}$ stacking on $\mathrm{Q}_{2}$ possible, since either their collectors or their emitters do not have to be connected together. Unlike the parasitic $\mathrm{p}+/ \mathrm{n}$-well/p-substrate PNP transistors, any two collectors must be tied together. For the three resistors with large resistance, the n-well was used to minimize the chip area. To measure the reference voltage, an extra unity gain buffer was also included. Fig. 4 shows the die microphotograph. The chip area without pads is about $0.029 \mathrm{~mm}^{2}$.

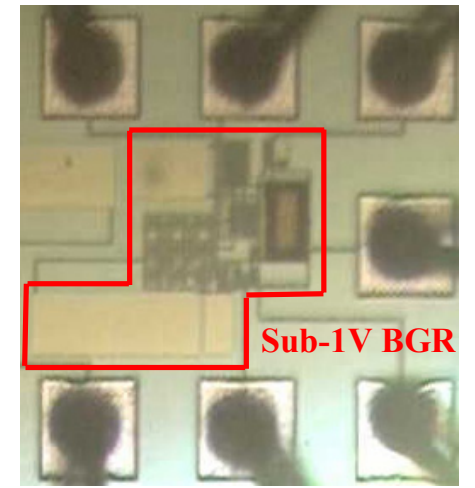

Fig. 4 Microphotograph of the proposed BGR circuit occupying the chip area of $0.029 \mathrm{~mm}^{2}$ without pads

Fig. 5 demonstrates the waveform of the sub-1V BGR circuit when the power supply is just turned on. The time for the reference voltage reaches $170 \mathrm{mV}$ within $15 \mathrm{~ms}$ which is shorter than the supply voltage switching time of $20 \mathrm{~ms}$, since the circuit starts to work at the supply voltage lower than $1 \mathrm{~V}$.

In Figs. 6 and 7, FF, TT and SS represent the simulated results of the fast, typical and slow process corners at $-20^{\circ} \mathrm{C}, 25^{\circ} \mathrm{C}$, and $100^{\circ} \mathrm{C}$, respectively. The measurement results well agree with the simulation data. Note that the measured data increased and decreased by steps is due to the resolution limitation of our oscilloscope. In Fig. 6, the measured reference voltages confined in the FF and SS corners almost keep the same value of $170 \mathrm{mV}$ for supply voltage from $0.95 \mathrm{~V}$ to $2.5 \mathrm{~V}$. Fig. 7 shows the variation of reference voltages as functions of temperature at supply voltage of $1 \mathrm{~V}$. Even though there are small deviations between the measured and simulated data, the measured values are within the same range and with the same trend of simulated results. It is worth noting that the variations of reference voltages for different process corners are much smaller than those using threshold voltages [5][6] instead of bandgap.

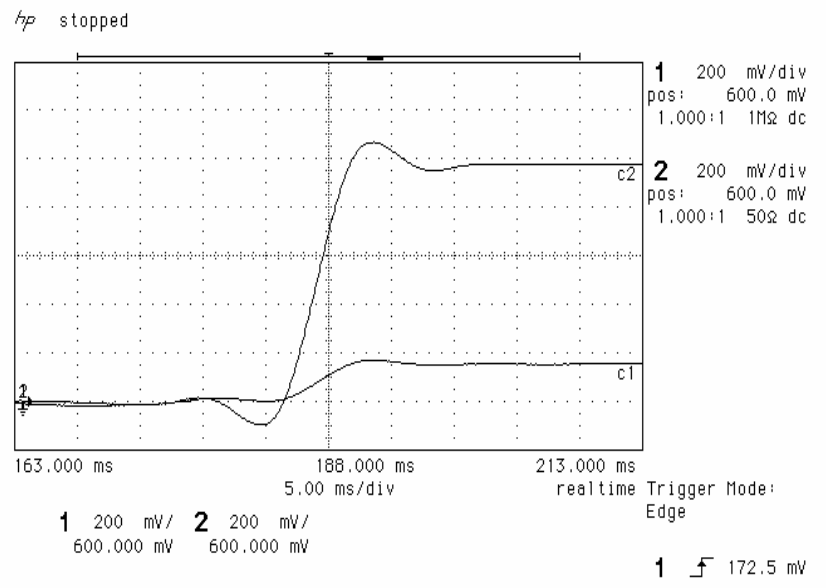

Fig. 5 The waveform of the reference voltage when the power supply is just turned on

Table II summarizes the performance.

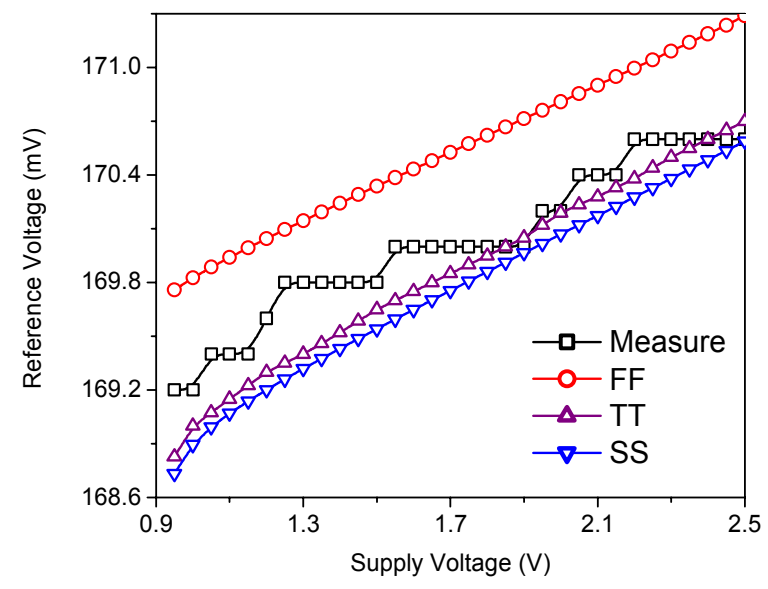

Fig. 6 The measured data are within the variation of different process corners at room temperature.

\section{CONCLUSIONS}

The proposed simple bandgap voltage reference circuit using parasitic NPN transistors without OP's achieves sub-1V and low-power operation. The circuit was fabricated using $0.18 \mu \mathrm{m}$ CMOS triple-well technology on chip area of $0.029 \mathrm{~mm}^{2}$. The variation of reference voltage is very small for various temperatures, supply voltages and process corners. The measurement results confirm those superior characteristics. It should be very useful to be applied to many analog circuits for sub-1V operations. 


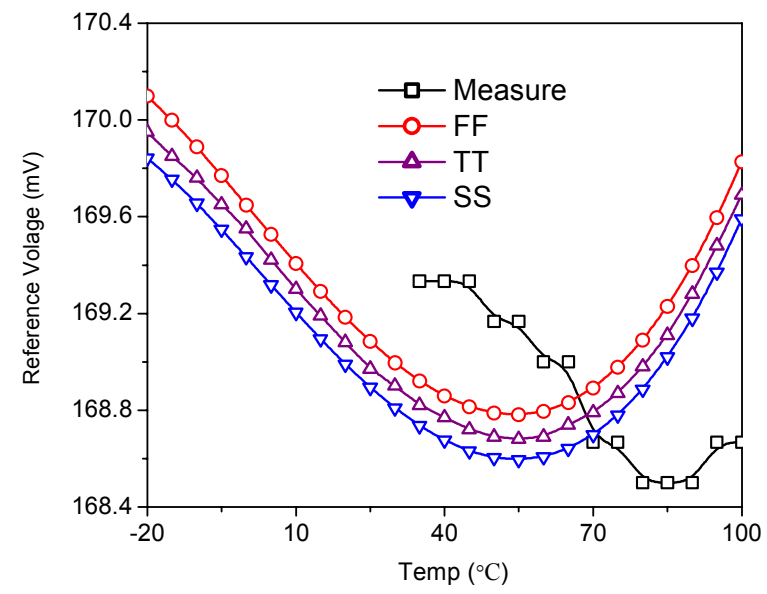

Fig. 7 Comparison of Measurement and data from different process corners for various temperatures at $1 \mathrm{~V}$ supply voltage

Table II The specifications of the proposed CMOS BGR circuit design

\begin{tabular}{|l|l|}
\hline Technology & $0.18 \mu \mathrm{m}$ CMOS \\
\hline Supply voltage & $0.95 \mathrm{~V} \sim 2.5 \mathrm{~V}$ \\
\hline Reference voltage & $169.4 \mathrm{mV}$ \\
\hline $\begin{array}{l}\text { Voltage variation }\left(-20^{\circ} \mathrm{C} \sim 100^{\circ} \mathrm{C} \text { at }\right. \\
\left.\mathrm{V}_{\mathrm{DD}}=1 \mathrm{~V}\right)\end{array}$ & $0.76 \%$ \\
\hline Voltage variation $\left(\mathrm{V}_{\mathrm{DD}}=1 \mathrm{~V} \sim 2.5 \mathrm{~V}\right)$ & $1.1 \mathrm{mV} / \mathrm{V}$ \\
\hline Total current $\left(\mathrm{V}_{\mathrm{DD}}=1 \mathrm{~V}\right)$ & $2.4 \mu \mathrm{A}$ \\
\hline Total resistance & $1280 \mathrm{~K} \Omega$ \\
\hline $\begin{array}{l}\text { Total Number of NPN transistors } \\
\text { (One is 8 times larger than the other. })\end{array}$ & 2 \\
\hline Area & $0.029 \mathrm{~mm}^{2}$ \\
\hline
\end{tabular}

\section{ACKNOWLEDGMENT}

The authors acknowledge the chip implementation center of National Science Council of Taiwan for their support in chip fabrication.

\section{REFERENCES}

[1] A. P. Brokaw, "Solid-State Regulated Voltage Supply," U.S. Patent 3887863, Jun. 3, 1975.

[2] James T. Doyle, Chandler, Ariz., "Low Power Digital CMOS Compatible Bandgap Reference," U.S. Patent 6075407, Jun. 13, 2000

[3] D. F. Mietus, "Reference Voltage Circuit Having a Substantially Zero Temperature Coefficient," U.S. Patent 5666046, Sep. 9, 1997

[4] H. Banba, H. Shiga, A. Umezawa, T. Miyaba, T. Tanzawa, S. Atsumi, and K. Sakui, "A CMOS Bandgap Reference Circuit With Sub-1-V Operation," IEEE J.
Solid-State Circuits, vol. 34, pp. 670-673, May 1999

[5] G. Serra-Graells, J. L. Huertas, "Sub-1-V CMOS Proportional-to-Absolute Temperature References," IEEE J. Solid-State Circuits, vol. 38, pp. 84-88, Jan. 2003

[6] G. Giustolisi, G. Palumbo, M. Criscione, and F. Cutri, "A Low-Voltage Low-Power Voltage Reference Based on Subthreshold MOSFETs," IEEE J. Solid-State Circuits, vol. 38, pp. 151-154, Jan. 2003

[7] E. Vittoz and J. Fellrath, "CMOS Analog Integrated Circuit Based on Weak Inversion Operation," IEEE J. Solid-State Circuits, vol. SC-12, no. 3, pp. 224-231, 1977 